\title{
ANÁLISE DA UTILIZAÇÃO DE TECNOLOGIAS DA INFORMAÇÃO MÓVEIS E SEM FIO (TIMS) NA CADEIA BOVINA: UM ESTUDO DE CASO NO ESTADO DE GOIÁS
}

\author{
Eliane Gomes Da Costa
}

elianegcosta@terra.com.br

Fundação Getúlio Vargas - São Paulo, SP / Brasil

Amarolinda Zanela Klein

aczanela@unisinos.br

Universidade do Vale do Rio dos Sinos - São Leopoldo, RS / Brasil

Luciana Marques Vieira

lmvieira@unisinos.br

Universidade do Vale do Rio dos Sinos - São Leopoldo, RS / Brasil

\begin{abstract}
Recebido em 28/09/2012
Aprovado em 12/06/2013

Disponibilizado em 01/04/2014

Avaliado pelo sistema double blind review

Revista Eletrônica de Administração

Editor: Luís Felipe Nascimento

ISSN 1413-2311 (versão on-line)

Editada pela Escola de Administração da Universidade Federal do Rio Grande do Sul.

Periodicidade: Quadrimestral

Sistema requerido: Adobe Acrobat Reader.
\end{abstract}

\section{RESUMO}

O crescente uso de Tecnologias da Informação (TI) tem influenciado a configuração de empresas em diversos setores da economia e provocado mudanças nas relações de trabalho, dos meios de produção, nas formas de comercialização, na comunicação, entre outros aspectos da vida organizacional. Por serem acessíveis em diversos locais e em diferentes formatos de dispositivos, as chamadas Tecnologias da Informação Móveis e Sem Fio (TIMS) vem sendo difundidas no agronegócio. O objetivo deste trabalho é analisar a utilização das TIMS nos diferentes elos da cadeia bovina, identificando os desafios e as oportunidades para o uso dessas tecnologias, bem como possíveis mudanças ou inovações geradas com a sua utilização. O método foi o de estudo de caso único, tendo como unidade de análise a cadeia da pecuária de corte do estado de Goiás. O estudo acessou especialistas e gestores de empresas pertencentes aos diferentes elos da cadeia (cria, recria, engorda, frigorífico e trader). Como principais resultados, percebeu-se que as TIMS contribuíram significativamente para o avanço nas práticas operacionais das empresas pesquisadas que adotam essas tecnologias, mas não para a gestão ou integração da cadeia. Problemas como o alto custo da tecnologia, a falta de infraestrutura de energia elétrica, de telecomunicações e de mão de obra qualificada, bem como o conservadorismo ao longo da cadeia e a falta de suporte às propriedades por parte dos fornecedores de tecnologia são algumas das principais barreiras para adoção das TIMS. Os ganhos obtidos com o uso dessa tecnologia estão relacionados a aprimoramentos no controle de estoque, produção, produtividade, segurança para os proprietários/acionistas, disponibilidade e qualidade das informações. Na produção destaca-se 
o controle individual dos animais, a redução nos erros de lançamento e uma melhor gestão nutricional. Com a utilização de brincos com códigos de barra ou eletrônicos (RFID) para controle individual do animal associado a um sistema de informação, é possível garantir a rastreabilidade. Na conclusão, o estudo destaca os resultados operacionais do uso das TIMS, mas apesar da literatura sugerir que elas podem ser utilizadas para melhor gestão da cadeia de suprimentos, não se identificou na pesquisa ações relevantes nesta direção.

Palavras-Chave: Tecnologias da Informação Móveis e Sem Fio; Cadeia bovina; Adoção de Tecnologia da Informação; Rastreabilidade.

\title{
ANALYSIS OF THE USE OF MOBILE AND WIRELESS INFORMATION TECHNOLOGY (MWIT) IN THE BEEF CHAIN: A CASE STUDY IN THE STATE OF GOIÁS (BRAZIL)
}

\begin{abstract}
The increasing use of Information Technology (IT) has influenced companies' configurations in several sectors and caused changes in labor relations, in production processes, in marketing strategies, communication, amongother elements of organizational life. Since these technologies are available at several locations through the use of different types of devices, the so-called Mobile andWireless Information Technology (MWIT) has been widespread in agribusiness. The goal of this paper is to analyze the use of MWIT in different agents of the beef chain. We have conducted a case study in the beef chain of the state of Goiás (Brazil), which holds $10.2 \%$ of all Brazilian livestock production. The paper aims to analyze the use of MWIT among distinguished agents throughout the beef supply chain. Secondly, it also identifies challenges and opportunities for the use of MWIT and, as it may cause changes and innovations. The method was the single case study, with the unit of analysis being the beef chain in the state of Goiás. Experts and companies 'managers, involved in the different value chain activities (nursing, raising, fattening and trading) were interviewed. Main findings pointed out that the use of MWIT contributes to operational practicesfor the organizations but, on the other, they do not contribute to the chain integration or management. Barriers to the use of the MWIT identified in this study are: technology high cost, lack of infrastructure of electrical energy and telecommunications, trained labor but also the conservative attitude of the chain members and lack of farm-level support by the technology suppliers. The benefits obtained with the use of MWIT are related to inventory control, production, productivity, security for owners/shareholders, availability and information quality. In the production process, the main benefits were the individual control of cattle, the reduction on data typing and also a better nutritional management.The use of earrings with code bar or electronic device (RFID) associated to an information system made possible to comply with traceability. As a conclusion, we highlight the operational use of MWIT, but although the literature suggests that these can be used to improve the supply chain management, these practices could not be identified in this case study.
\end{abstract}

Keywords: Mobile and Wireless Information Technology (MWIT); Beef Chain; Information Technology Adoption; Traceability.

REAd | Porto Alegre - Edição 77 - N 1 - janeiro/abril 2014 - p. 140-169 
Análise da utilização de Tecnologias da Informação Móveis e Sem Fio (TIMS) na cadeia bovina: um estudo de caso no estado de Goiás

\section{INTRODUÇÃO}

O uso crescente de Tecnologias da Informação (TI) tem modificado substancialmente a configuração de empresas em diversos setores da economia mundial. Estas mudanças estão ocorrendo nos campos das relações de trabalho, dos meios de produção, nas formas de comercialização, nos meios de comunicação, entre outros. No agronegócio, em especial na pecuária de corte, não tem sido diferente.

O Brasil é atualmente o maior exportador mundial de carne (ASSOCIAÇÃO BRASILEIRA DE INDÚSTRIAS EXPORTADORAS DE CARNE, 2011). O país possui o maior rebanho do mundo e também se destaca por ter a maior área livre de incidência da febre aftosa, condição favorável para manutenção do comércio exterior. A Organização Mundial de Saúde Animal (OIE) está preocupada com as discrepâncias entre os padrões nacionais de identificação de animais vivos e sistemas de rastreabilidade dos produtos de origem animal. Este fato coloca em risco as políticas de exportação dos países em desenvolvimento, podendo, em última instância, perder o acesso a determinados mercados em função de barreiras comerciais, que por vezes são postas em prática como resultado dessas discrepâncias (ORGANIZAÇÃO DAS NAÇÕES UNIDAS, 2006).

Em 1996, quando foi diagnosticada a doença "da vaca louca" na Inglaterra, a população mundial passou a exigir mais segurança e sanidade na produção de alimentos. Preocupados com a qualidade dos alimentos importados, autoridades governamentais desenvolveram manuais estabelecendo padrões mínimos de qualidade e produção para garantir a segurança alimentar. Corroborando esta preocupação, Machado (2000) afirma que o desafio para a indústria de alimentos é fornecer ao consumidor segurança de informação e destaca que a qualidade alimentar está diretamente relacionada à capacidade da cadeia em reduzir a assimetria de informação. Uma forma encontrada para garantir a segurança alimentar dos produtos cárneos foi a criação da monitoração do gado, denominada de rastreabilidade.

Inicialmente, o meio utilizado para rastrear o gado era a marcação no couro que evoluiu para os brincos, até chegar aos chips. O uso desta última tecnologia foi potencializada pela difusão das mais recentes Tecnologias da Informação Móveis e Sem Fio (TIMS), que incluem dispositivos como: brincos de identificação com código de barras, chip intraruminal monitorado por rádio frequência (RFID), PDAs para coleta de informações no campo e notebooks, entre outros. Ao estarem disponíveis em diferentes locais e em diferentes formatos

REAd | Porto Alegre - Edição 77 - N 1 - janeiro/abril 2014 - p. 140-169 
Eliane Gomes Da Costa, Amarolinda Zanela Klein \& Luciana Marques Vieira

de dispositivos, as TIMS podem proporcionar aos players da cadeia produtiva de gado informações seguras e atualizadas online.

Conforme apontam Sorensen et al. (2008) e Sorensen (2011), as TIMS desempenharão cada vez mais um papel significativo para as organizações, ao promover inovações no que se refere a novas formas de se organizar uma empresa, local de trabalho, trabalho em equipe, podendo colaborar para o aumento da eficiência e eficácia organizacional, e, no caso analisado, para melhor gerenciamento da cadeia de suprimentos.

Considerando a disseminação das TIMS na cadeia produtiva de gado, torna-se pertinente, portanto, verificar que tipos de inovações ou mudanças estão ocorrendo nos processos dessa cadeia. Seguindo a discussão proposta no Manual de Oslo (OECD, OCDE, 2004), acredita-se atualmente que o desenvolvimento e a difusão de novas tecnologias são essenciais para o crescimento da produção e aumento da produtividade, contudo, nosso entendimento do processo de inovação e seu impacto econômico ainda é deficiente. Vivemos uma importante revolução tecnológica, com a economia mundial sendo reconfigurada, entre outras, pelas novas Tecnologias da Informação. Apesar disso, essas alterações tecnológicas nem sempre se refletem diretamente em aumentos de produtividade e competitividade.

Inovação é entendida neste artigo, de forma ampla, como o desenvolvimento e implementação de novas ideias por pessoas que se relacionam com outras em um contexto institucional (VAN DE VEN, 1986). De forma mais específica, no contexto organizacional, a inovação pode se dar de várias formas (SCHUMPETER, 1934), desde a introdução de novos produtos, a abertura de novos mercados, o desenvolvimento de fontes alternativas de insumos, a criação de novas estruturas de mercado e a introdução de novos métodos de produção.

Conforme o Manual de Oslo (OECD, OCDE, 2004) uma inovação tecnológica de produto envolve a implantação/comercialização de um produto com características de desempenho superiores, de modo a fornecer ao consumidor serviços novos ou aprimorados. Já uma inovação de processo tecnológico envolve a implantação/adoção de métodos de produção ou comercialização novos ou significativamente aprimorados, podendo envolver mudanças de equipamento, recursos humanos, métodos de trabalho ou uma combinação destes.

Considerando esses conceitos, neste artigo, busca-se analisar o nível de difusão das TIMS na cadeia do gado e compreender se, e como, o uso de TIMS vem provocando mudanças e inovações no contexto dessa cadeia, especialmente inovações em nível de estrutura da cadeia (ex.: relacionamento e troca de informações entre os elos), produtos (ex.:

REAd | Porto Alegre - Edição 77 - N 1 - janeiro/abril 2014 - p. 140-169 
Análise da utilização de Tecnologias da Informação Móveis e Sem Fio (TIMS) na cadeia bovina: um estudo de caso no estado de Goiás

inserção de informações de rastreabilidade para garantia da qualidade) e processos (ex.: novas formas de trabalho e gestão na cadeia).

$\mathrm{O}$ artigo relata os resultados de um estudo de caso na cadeia bovina de Goiás. Esse estado concentra 10,2\% de todo o rebanho brasileiro (BRASIL, 2009) sendo que "esta atividade econômica é responsável por $10,26 \%$ de toda riqueza gerada no Estado" (SECRETARIA DO PLANEJAMENTO E DESENVOLVIMENTO DO ESTADO DE GOIÁS, 2008, p. 8). Desta forma, o estudo trata de uma problemática atual e relevante não somente para a cadeia de suprimentos em análise, mas para outras que devem atender aos mesmos padrões de integração de informações produtivas para atender aos seus mercados (por exemplo, a cadeia de frutas para exportação localizada no nordeste brasileiro).

O estudo procura identificar os desafios e as oportunidades para a adoção do uso das TIMS na cadeia bovina, visto que tais tecnologias promovem possibilidades de inovação e melhoria da produção local, o que pode aumentar a competitividade dos produtores e, consequentemente, a melhoria da posição econômica do Estado. Do ponto de vista acadêmico, a pesquisa procura contribuir para reduzir a lacuna existente de trabalhos que versam sobre o uso de TI e de TIMS na cadeia pesquisada e as decorrências de uso para o gerenciamento dessa cadeia. Cabe comentar que verificou-se trabalhos publicados anteriormente que tratam separadamente as questões de TI e rastreabilidade, sem abordar de forma sistemática o uso das TIMS.

Este artigo está estruturado da seguinte forma: na próxima seção (2) são tratados os aspectos teóricos relacionados aos objetivos da pesquisa. Na sequência, (seção 3) descreve-se o método de pesquisa, detalhando as etapas realizadas. Na seção 4 faz-se uma discussão dos resultados obtidos, confrontando-os com a teoria. Na seção 5 apresentam-se as conclusões do estudo, ressaltando implicações gerenciais, contribuições do trabalho e proposições para futuras pesquisas.

\section{REFERENCIAL TEÓRICO}

Esta seção apresenta os principais conceitos sobre a temática estudada encontra-se estruturada da seguinte forma: na primeira parte apresentam-se as Tecnologias da Informação Móveis e Sem Fio (TIMS) bem como a questão da mobilidade. Na segunda parte, discorre-se sobre a utilização das TIMS na Gestão da Cadeia de Suprimentos (SCM). Na terceira parte, aborda-se as Tecnologias da Informação e TIMS utilizadas na Cadeia Bovina.

REAd | Porto Alegre - Edição 77 - N 1 - janeiro/abril 2014 - p. 140-169 


\subsection{Tecnologias de Informação Móveis e Sem Fio (TIMS)}

Kalakota e Robinson (2002) entendem por Tecnologias de Informação Móveis todo e qualquer dispositivo de informação que possa ser facilmente transportado. Um exemplo seria um laptop comum, sem a possibilidade de acesso a redes sem fio."Já as Tecnologias de Informação Sem Fio (wireless) são tecnologias que envolvem o uso de dispositivos conectados a uma rede ou a outro aparelho por links de comunicação sem fio, como, por exemplo, as redes de telefonia celular ou a transmissão de dados via satélite" (SACCOL e REINHARD, 2007, p. 179). Para Saccol (2005, p. 13), “Tecnologias da Informação Móveis e Sem Fio (TIMS) são ferramentas de Tecnologia da Informação que permitem o acesso a dados e à comunicação pessoal de forma móvel, via acesso a redes sem fio. Como exemplos dessas tecnologias estão o telefone celular, palmtops, telefones inteligentes, PDAs ou laptops habilitados à conexão com redes sem fio, assim como aplicações de RFID (Radio Frequency Identification) e todos os sistemas de informação acessados por meio desses dispositivos".

As TIMS têm um grande potencial de utilização na gestão da cadeia de suprimentos (Supply Chain Management - SCM), uma vez que as atividades realizadas em uma cadeia ocorrem em diferentes locais e momentos, e muitas delas envolvem um trabalho em movimento. A identificação por rádio frequência (Radio Frequency Identification - RFID) é um exemplo de TIMS que promete reduzir os gaps de informação na cadeia de suprimentos (ANGELES, 2005; SARAC e ABSI, 2010). A etiqueta de RFID é composta por um microchip e uma antena. O microchip armazena as informações do objeto, identificando-o com um único serial. A antena transmite as informações do microchip para um leitor que, por sua vez, transforma os dados em informações para os computadores. Esta tecnologia aumenta a transparência entre os elos da cadeia e gera benefícios como: redução do tempo para reorganizar transferências de materiais; redução de roubo; melhora do rastreamento de pallets, caixas e produtos individuais; melhor planejamento e otimização de estoques e ativos reutilizáveis (COLTMAN, GADH e MICHAEL, 2008).

Para Kalakota e Robinson (2002), a economia móvel (m-economy) é irreversível, o movimento de convergência da internet, do e-business e das telecomunicações com e sem fio estão obrigando as empresas a reverem seu modus operantis, que passa a ser melhor compreendido, entendendo uma nova cadeia de valor que combina: os tipos de aparelhos móveis, acesso sem fio e conteúdo.

O uso das Tecnologias de Informação e Comunicação (TIC) móveis resulta em um novo paradigma sobre como conduzir uma empresa de agora em diante. Para os profissionais 
Análise da utilização de Tecnologias da Informação Móveis e Sem Fio (TIMS) na cadeia bovina: um estudo de caso no estado de Goiás

de uma forma geral, sua produtividade pode ser medida e/ou acompanhada em qualquer lugar no espaço. As TIC móveis também proporcionam aos trabalhadores acesso à dados ou base de dados, independentemente do lugar em que estejam. Entretanto, este benefício é apenas a ponta do iceberg, há muito que desenvolver, principalmente transformando as organizações, a cadeia de suprimentos e o mercado (BASOLE, 2008).

\subsection{A Gestão da Cadeia de Suprimentos (SCM)e a utilização de TIMS}

Mentzer et al. (2001) definem Supply Chain como sendo um conjunto de três ou mais entidades (organizações ou indivíduos) diretamente envolvidas nos fluxos a montante e a jusante de produtos, serviços, finanças e/ou informações de uma fonte a um cliente. Ainda segundo os autores, a oferta globalizada tem forçado as empresas a buscarem formas mais eficazes de coordenar o fluxo de materiais dentro e fora da empresa. A chave para essa coordenação é uma orientação para relações mais estreitas com fornecedores, conhecida como Supply Chain Management (SCM), ou seja, gestão da cadeia de suprimentos. Empresas têm procurado desenvolver modelos de gestão e operação que as mantenham no mercado e dentre estes métodos destaca-se o autofornecimento, o planejamento colaborativo, o compartilhamento de informações, o controle do processo logístico e a reposição contínua (BOWERSOX, CLOSS e STANK, 2000; SADLER e HINES, 2002; KÄRKKÄINEN e HOLMSTRÖM, 2002).

Dentre as tendências que facilitam a colaboração nas cadeias de abastecimento destaca-se a necessidade de compartilhar informação. "O compartilhamento de informações em toda a cadeia de abastecimento é o catalisador que permite a integração eficaz" (BOWERSOX, CLOSS e STANK, 2000, p. 10). Para que este modelo seja bem sucedido, os autores destacam três pontos de atenção: o primeiro pressupõe alto grau de confiança dentro da empresa estendendo-se a toda a cadeia de suprimento. O segundo aspecto é que, inicialmente, tende-se a compartilhar dados táticos, como previsões de curto prazo e disponibilidade de estoque que podem facilitar o planejamento de recursos e fluxo do produto. O terceiro aspecto é que a informação deve ser entendida como um recurso fundamental para gerir o intercâmbio de forma confidencial, reduzindo os conflitos na condução dos negócios com os fornecedores e concorrentes.

Para Lefebvre et al. (2006), Kärkkäinen e Holmström (2002), na gestão da cadeia de suprimentos (SCM), o RFID não é apenas uma tecnologia que possibilita a identificação de pallets ou produto mas uma tecnologia que aumenta o nível de integração dos processos na 
Eliane Gomes Da Costa, Amarolinda Zanela Klein \& Luciana Marques Vieira

relação business-to-business (B2B) e promove o compartilhamento de informações entre as operações, gerando grandes mudanças na política, cultura, desempenho e estrutura organizacional. Outros exemplos de aplicação e benefícios do RFID na cadeia de abastecimento é que, uma vez acoplada a sensores, é possível estabelecer controles rigorosos em níveis pré-determinados de temperatura, pressão, umidade, distância ou profundidade, economizando assim recursos consideráveis na operação.

Entretanto, a tecnologia de RFID encontra algumas barreiras de difusão. Ela ainda não é bem compreendida fora dos laboratórios, o uso de etiquetas requer testes extensivos, e as empresas ainda não estão dispostas a participar efetivamente com recursos. Outra preocupação empresarial recai sobre a invasão de privacidade (COLTMAN, GADH e MICHAEL, 2008). A implantação de um sistema de RFID requer investimentos consideráveis e isso representa um esforço considerável para qualquer empresa. Outra questão importante é que, devido à falta de conhecimento das dimensões do RFID para atender aos requisitos de negócio, nem mesmo os vendedores deste sistema conseguem "prescrever" a melhor solução para a empresa.

Para Parabhu et al. (2006), os benefícios da implantação do RFID serão distintos à medida que algumas etapas de maturidade e complexidade da tecnologia sejam ultrapassadas. Acredita-se que no primeiro momento o foco volta-se para o controle da movimentação de produtos nos armazéns; num segundo momento, a utilização das etiquetas nas embalagens dos produtos passa a ser necessária frente às frequentes faltas de mercadoria, o que ressalta a necessidade de planejamento e, por fim, na terceira etapa a etiqueta passa a ser aplicada no produto (individualizado), proporcionando uma reposição mais eficiente, garantindo estoques mínimos, previsões de demanda, etc. Os autores ainda apresentam alguns desafios para a adoção do RFID, tais como: o compartilhamento de dados; definição dos elos que fornecerão e receberão informações; que tipo de informação será compartilhada; como, quando e onde as informações serão capturadas; por quanto tempo os dados precisarão ser armazenados; o formato em que os dados precisarão ser encaminhados; as regulamentações; a quantidade de leitores; a estrutura da rede descentralizada para a coleta de dados.

Lefebvre et al. (2006), Kärkkäinen e Holmström (2002) afirmam que o RFID é uma tecnologia que apoiará novos modelos de negócio, promovendo a integração eletrônica entre os elos da cadeia de abastecimento. Reconhecem também que a tecnologia encontra-se em fase embrionária, mas acreditam que é uma questão de tempo para se fixar dentro das organizações. Destacam ainda que o sucesso da implantação é fortemente dependente da 
Análise da utilização de Tecnologias da Informação Móveis e Sem Fio (TIMS) na cadeia bovina: um estudo de caso no estado de Goiás

visão, vontade e capacidade dos elos da cadeia de abastecimento em capturar dados em tempo real, de forma continuada, mantendo as informações atualizadas nos produtos conforme eles se movem pela cadeia de abastecimento.

Strassner e Schoch (2002) apresentam dois tipos de TIMS que também são muito utilizadas para a gestão de atividades na cadeia de suprimentos. A primeira é o Global Positioning System (GPS) ou Sistema de Posicionamento Global, utilizando uma técnica de triangulação, um receptor de GPS identifica quatro satélites e transmite as coordenadas de localização a uma central que, então, poderá utilizá-la para, por exemplo, bloquear o funcionamento de um veículo que encontra-se fora de rota. A segunda tecnologia, são os chamados sensores do tipo térmico, acústico, visual, infravermelho, magnéticos e sísmicos, ou ainda, de radar para monitorar condições de temperatura, umidade, circulação de veículos, iluminação, pressão, composição do solo, níveis de ruído, presença ou ausência de certos tipos de objetos etc. Estes sensores são responsáveis por capturar um dado que por sua vez será transmitido para um sistema de gerenciamento.

Para Strassner e Schoch (2002), as tecnologias de informação tradicionais como ERP (Enterprise Resource Planning) e sistemas de e-business não são suficientes para manter o negócio competitivo. Problemas como erros humanos e atraso (delay) no acesso à informação são razões que os tornam ineficientes. A alternativa proposta destaca o uso de TIMS, pois acredita-se que com menos intervenção humana, acrescida da intensificação do uso de recursos tecnológicos autônomos (RFID, sensores e localizadores), seja possível melhorar o desempenho na cadeia de suprimentos.

Segundo Siau e Shen (2002) as TIMS provocarão mudanças fundamentais na gestão da cadeia de suprimentos. Serão ferramentas importantes para apoiar os tomadores de decisão que precisam atender prontamente às necessidades do mercado, melhorando a comunicação organizacional e os relacionamentos com seus clientes e fornecedores. Para Kalakota e Robinson (2002, p. 175), “dentro da estrutura da cadeia de suprimentos existem quatro segmentos, considerados principais, nos quais as TIMS terão impacto significativo: (1) compras eletrônicas (compras, aprovações e pagamento); (2) execução da cadeia de suprimentos (gerenciamento do estoque, logística e entrega); (3) visibilidade da cadeia de suprimentos (rastreamento do ativo, recebimento e coleta de dados); (4) gerenciamento do serviço (logística reversa, automação da força de campo e o gerenciamento da expedição)".

Dentre os benefícios do uso de soluções de TIMS para a cadeia de suprimentos destacam-se: simplificação do processo do pedido-até-o-pagamento, precisão na coordenação 
Eliane Gomes Da Costa, Amarolinda Zanela Klein \& Luciana Marques Vieira

do processo de execução do pedido, melhor rastreamento e utilização dos ativos e gerenciamento de serviços mais acessível (KALAKOTA e ROBINSON, 2002).

De um modo geral, conclui-se que a aplicação das TIMS na cadeia de suprimentos proporciona ganhos de agilidade, controle e integração interessante do ponto de vista da competitividade econômica. Entretanto, entende-se que a aplicação destas tecnologias ainda encontra-se em estágio inicial.

\subsection{Tecnologias da Informação e TIMS utilizadas na Cadeia Bovina}

Uma das principais aplicações das TIMS na cadeia bovina refere-se à rastreabilidade dos produtos para garantir a segurança alimentar, considerado fator crucial para a competitividade nesse setor. Para a Organização Mundial de Saúde Animal (2008) há vários fatores que podem determinar a escolha do sistema de identificação e rastreabilidade animal. Entretanto, na concepção do sistema, deve-se considerar fatores como: os resultados da análise de risco, a situação de saúde pública e animal e programas relacionados a dados da população animal (tais como espécie e raças, números e distribuição), os tipos de produção, os padrões de trânsito animal, as tecnologias disponíveis, o comércio de animais e de produtos de animais, as análises de custo/benefício e outras considerações econômicas, geográficas e ambientais, além de aspectos culturais.

A obrigatoriedade da rastreabilidade e da implantação de uma base de dados proporcionou a TI assumir papel de "catalisador da redução das especificidades de ativos, eliminando principalmente as barreiras geográficas, os erros e o tempo necessário para aquisição e uso de informação de rastreabilidade, além de facilitar a coordenação pela capacidade de conexão rápida de todos os agentes da cadeia produtiva" (MACHADO e ZYLBERSZTAJN, 2004, p. 49).

Golan et al. (2003) e Ferreira e Vieira (2005), apontam a rastreabilidade como sendo um agente de integração na cadeia agroalimentar. A necessidade de se registrar e disponibilizar informações ao longo de todo o processo produtivo fortalece os sistemas de rastreamento. Neste processo de integração, destacam-se os benefícios do compartilhamento da informação, ou seja, a possibilidade de rastrear o produto, seja no sentido produtor -> consumidor, seja no sentido oposto, consumidor -> produtor, passando por toda a cadeia (GOLAN et al., 2003). 
Análise da utilização de Tecnologias da Informação Móveis e Sem Fio (TIMS) na cadeia bovina: um estudo de caso no estado de Goiás

No Brasil, o Governo Federal publicou a Instrução Normativa n. 17, de 13 de julho de 2006, que regulamenta o Serviço de Rastreabilidade da Cadeia Produtiva de Bovinos e Bubalinos (SISBOV). De acordo com a instrução, todos os bovinos e bubalinos dos estabelecimentos rurais aprovados no SISBOV, serão, obrigatoriamente, identificados individualmente e cadastrados na Base Nacional de Dados (BND) com o registro de todos os insumos utilizados na propriedade durante o processo produtivo. Quanto ao sistema de identificação, a numeração é única, de 15 dígitos, e o produtor pode escolher o sistema de identificação: um brinco e um botton padrão; um brinco ou um botton padrão e um dispositivo eletrônico; um brinco padrão em uma orelha e uma tatuagem na outra; um brinco padrão e o número de manejo do SISBOV marcado a fogo; um dispositivo único com identificação visual e eletrônica ou somente um brinco padrão. A adesão ao SISBOV é voluntária, entretanto, obrigatória no caso de comercialização para mercados que exigem a rastreabilidade. Este sistema abarca todos os elos da cadeia produtiva. Para aderir ao sistema o produtor precisa receber um certificado, que só poderá ser emitido por empresas (Certificadoras) credenciadas junto ao Mapa (MINISTÉRIO DA AGRICULTURA, PECUÁRIA E ABASTECIMENTO, 2006).

Para Ribeiro et al. (2007) os brincos identificadores não são suficientes para o rastreamento total das características dos animais e do transporte destas informações pela cadeia de suprimento. Uma solução apontada pelos autores, baseada em experiências de países desenvolvidos, seria a utilização do RFID. Dentre os estímulos para tal mudança, destaca-se o acesso a informações de forma detalhada, como por exemplo, o consumidor ter acesso às informações de origem do animal abatido fazendo a leitura da etiqueta da embalagem no ponto de venda. Outro benefício para adesão ao RFID é a alta resistência das etiquetas, o atual dispositivo (brinco) pode ser perdido durante o manejo, dificultando o processo de rastreabilidade, além de ser descartado quando do abate do animal, gerando assim, um novo custo para o criador. Uma desvantagem apresentada pelos autores é o custo de implantação, ainda elevado, se comparado ao sistema tradicional de brincos.

Segundo Smith e Phillips (2002), existe uma relação intrínseca entre a arquitetura do sistema de identificação e rastreabilidade e o sistema de produção, armazenamento, distribuição e comercialização, ou seja, o sistema de rastreabilidade deve permitir acesso às informações geradas em todas as etapas produtivas. Caso isso não ocorra, a perda de informações pode afetar todo o fluxo da rastreabilidade nas demais etapas da cadeia produtiva.

REAd | Porto Alegre - Edição 77 - N 1 - janeiro/abril 2014 - p. 140-169 
Eliane Gomes Da Costa, Amarolinda Zanela Klein \& Luciana Marques Vieira

Para Conceição e Barros (2005) a realização de procedimentos de rastreabilidade depende fundamentalmente das dificuldades de acesso a processos produtivos ao longo da cadeia agroalimentar. Estes procedimentos, além de constituírem um instrumento essencial de gestão de risco e permanente retroalimentação do processo produtivo, proporcionam o alcance de objetivos como: monitoramento e controle de sistemas de avaliação de conformidade; garantia da oferta de alimentos inócuos à saúde humana; prevenção da propagação de pontos críticos de contaminação.

Resende e Lopes (2004) acreditam que em um futuro próximo os rebanhos cadastrados em programas de rastreabilidade acabarão sendo diferenciados dos demais e deverão ter maior procura e valorização. Um sistema de rastreabilidade para a cadeia bovina deve, de acordo com Resende e Lopes (2004, p. 9-12): definir um sistema de códigos de padrão internacional para os animais e cortes; escolher um ou mais sistemas de identificação (tatuagem, brinco, chip, etc) e ter uma tecnologia (ferramenta) de informação informatizada. Quanto às funções e atividades a serem realizadas, para efetivar um sistema de rastreabilidade destaca-se: a utilização de sistemas de identificação animal; sistemas de processamento, armazenagem e gerenciamento dos dados; auditoria e verificação dos dados em campo.

De acordo com Machado e Zylbersztajn (2004), a identificação eletrônica pode diminuir custos de rastreabilidade da carne bovina, pois reduz o tempo de aquisição e de uso da informação. A identificação eletrônica também facilita a coordenação com o princípio do incentivo baseado em remuneração da carne pelo critério de qualidade da carcaça. Com a consolidação de sistemas de qualidade certificados e com o suporte de TI para manter o fluxo de informações, o mercado como um todo fica mais transparente, possibilitando transações coordenadas.

Ribeiro, Scavarda e Batalha (2007, p. 9-10) destacam como benefícios das etiquetas de RFID: "a possibilidade de leitura livre de erros a uma distância de 0,8 m (considerando que um animal se movimenta a uma velocidade de $4 \mathrm{~m} / \mathrm{s}$ ); facilidade de leitura; identificação simultânea; capacidade de armazenamento; baixo tempo de resposta; transporte de informação; confiabilidade; durabilidade; dificuldade de falsificação". Como dificuldades de uso, os autores destacam que a presença de água e/ou metal pode fazer com que a taxa de leitura decline: "isso ocorre porque líquidos absorvem as ondas de rádio e os metais as refletem; os custos também são fatores impeditivos".

Do ponto de vista da gestão, as TIMS aplicadas à cadeia bovina podem colaborar nos processos de: (a) controle de estoque do gado (quando utilizada a identificação eletrônica e 
Análise da utilização de Tecnologias da Informação Móveis e Sem Fio (TIMS) na cadeia bovina: um estudo de caso no estado de Goiás

individual); (b) na tomada de decisão de vendas, ou seja, qual animal está no ponto de abate, utilizando-se de balanças eletrônicas é possível gerenciar esta informação a cada necessidade de manejo; (c) decisão de compra de suprimentos alimentares e/ou escolha de pasto, com base na análise de peso do rebanho; (d) rastreabilidade, registrando-se online toda informação exigida pelos órgãos reguladores. Quanto às tecnologias de telecomunicações, a internet proporciona mobilidade aos gestores e/ou diretores das empresas rurais. O somatório do uso da internet e de um sistema de informação permite que a gestão seja feita à distância (CÓCARO e JESUS, 2007).

Com base na revisão da literatura conclui-se que existem diversas possibilidades de aplicação das TIMS para potencializar a competitividade na cadeia bovina. Por meio de um estudo empírico (cuja metodologia é descrita a seguir), buscou-se verificar a aplicação (ou não) dessas tecnologias na prática, bem como facilitadores e barreiras para seu uso.

\section{MÉTODO E PROCEDIMENTOS}

O estudo de caso como estratégia para a realização desta pesquisa se justifica por pressupor a falta de controle sobre eventos comportamentais e um grau de enfoque em acontecimentos contemporâneos (YIN, 2005). Foi realizado um estudo de caso único com unidades incorporadas de análise, que se fundamenta pela representatividade e/ou tipicidade, ou seja, as lições aprendidas com esses casos fornecem muitas informações sobre as experiências das empresas, pessoas, etc., envolvidas na pesquisa (YIN, 2005). O objeto de estudo foi a cadeia bovina do estado de Goiás analisada sob a ótica de três unidades de análise incorporadas consideradas os principais elos da cadeia: produtor (cria, recria e engorda), frigorífico e trader.

Cabe salientar que para a realização da pesquisa desenvolveu-se o protocolo do caso, contendo todo o planejamento da coleta de dados e os roteiros de entrevista. Este protocolo foi previamente validado por dois especialistas acadêmicos e um especialista de mercado.

O estudo de caso foi dividido em duas etapas: uma etapa de exploração e outra descritiva. Na etapa de exploração, o objetivo foi gerar insights e ganhar familiaridade com a área do tema de pesquisa para proceder com as investigações (COLLINS e HUSSEY, 2005; CRESWELL, 2007). Para Hair et al. (2005), a pesquisa exploratória é orientada para a descoberta, sendo assim, não têm a intenção de testar hipóteses específicas de pesquisa. 
A etapa de exploração da pesquisa foi realizada em dois momentos. O primeiro contemplou um levantamento de estudos prévios sobre a cadeia. O segundo realizou-se por meio de entrevistas semiestruturadas com nove (9) pessoas provenientes de: empresas que fornecem TIMS para uso na cadeia pesquisada; representantes das entidades de classe do estado de Goiás (para compreender suas percepções sobre o tema na cadeia pesquisada) e certificadoras (para compreender o processo de certificação e da rastreabilidade). O Quadro 1 apresenta o detalhamento dessas entrevistas.

$\mathrm{Na}$ segunda etapa da pesquisa, de natureza descritiva, foram entrevistados representantes de cada um dos elos da cadeia (produtor, frigorífico e exportadores). Os entrevistados foram, em geral, responsáveis diretos (gerentes, encarregados e proprietários) pelas empresas pesquisadas. No total foram realizadas treze (13) entrevistas, totalizando aproximadamente $8,5 \mathrm{~h}$ de gravação. No elo produtor, foram entrevistados representantes de nove (9) propriedades: Vera Cruz (gerente de pecuária), Terra Santa (proprietária), Fazenda Furna do Mateiro (proprietário), Fazenda Califórnia (gerente), Fazenda Rromy (gerente), Confinamento Bertin (gerente de rastreabilidade), Fazenda Acará (gerente), Grupo Macaé (proprietário) e Fazenda Conforto (encarregado de escritório), sendo que em seis (6) organizações as entrevistas foram realizadas durante visita para observação in loco com o objetivo de enriquecer a compreensão do problema de pesquisa. Nas demais (três propriedades), as entrevistas foram realizadas por telefone em função da dificuldade de deslocamento e disponibilidade de agenda dos responsáveis. No elo trader, entrevistou-se o JBS Global (UK) Ltd., representado pelo seu gerente. No elo frigorífico, entrevistou-se o gerente de rastreabilidade do JBS (unidade Goiânia). O Quadro 2 sintetiza os detalhes dessas entrevistas.

Quadro 1 - Detalhamento das entrevistas realizadas na etapa exploratória

\begin{tabular}{|c|c|c|c|c|c|c|}
\hline \multicolumn{2}{|r|}{ ELO DA CADEIA } & EMPRESA & CARGO & DATA & DURAÇÃO & FORMA \\
\hline \multirow{3}{*}{\multicolumn{2}{|c|}{\begin{tabular}{|c|c|}
1 & FORNECEDORES DE \\
2 & $\begin{array}{c}\text { TIMS } \\
3\end{array}$
\end{tabular}}} & FARM TECH & Proprietário & $16 / 05 / 10$ & $0: 39: 22$ & IN LOCO \\
\hline & & GESTÃO AGROPECUÁRIA & Proprietário & $26 / 05 / 10$ & $0: 40: 21$ & IN LOCO \\
\hline & & HANA INNOSYS & Presidente & $21 / 05 / 10$ & 0:09:28 & IN LOCO \\
\hline \multirow{3}{*}{\begin{tabular}{l|}
$\frac{4}{5}$ \\
6 \\
\end{tabular}} & \multirow{3}{*}{$\begin{array}{l}\text { ENTIDADES DE } \\
\text { CLASSE }\end{array}$} & FAEG & Assessora Técnica & $06 / 05 / 10$ & 1:19:44 & IN LOCO \\
\hline & & APROVA & Presidente & $06 / 05 / 10$ & 0:59:00 & IN LOCO \\
\hline & & SGPA & Vice Presidente & $24 / 02 / 10$ & $0: 59: 55$ & IN LOCO \\
\hline \multirow{2}{*}{7} & \multirow{3}{*}{ CERTIFICADORAS } & \multirow{2}{*}{$\begin{array}{l}\text { OXXEN TECNOLOGIA EM } \\
\text { RASTREABILIDADE }\end{array}$} & Proprietário & $28 / 04 / 10$ & 0:55:08 & IN LOCO \\
\hline & & & Proprietário & $28 / 04 / 10$ & $0: 23: 28$ & IN LOCO \\
\hline 8 & & PLANEJAR & Executiva de Negócios & $14 / 05 / 10$ & $0: 33: 46$ & IN LOCO \\
\hline & & & & TOTAL & $6: 40: 12$ & \\
\hline
\end{tabular}

Fonte: Dados da pesquisa

REAd | Porto Alegre - Edição 77 - N 1 - janeiro/abril 2014 - p. 140-169 
Análise da utilização de Tecnologias da Informação Móveis e Sem Fio (TIMS) na cadeia bovina: um estudo de caso no estado de Goiás

Quadro 2 - Detalhamento das entrevistas realizadas na etapa descritiva

\begin{tabular}{|c|c|c|c|c|c|c|}
\hline \multicolumn{2}{|c|}{ ELO DA CADEIA } & EMPRESA & CARGO & DATA & DURAÇÃO & FORM A \\
\hline 1 & TRADE & JBS GLOBAL (UK) Ltd. & Gerente & $28 / 05 / 10$ & $1: 10: 31$ & Telefone \\
\hline 2 & \multirow{11}{*}{ PRODUTORES } & VERA CRUZ & Gerente de Pecuária & $30 / 04 / 10$ & 1:30:04 & IN LOCO \\
\hline 3 & & TERRA SANTA & Proprietária & $22 / 05 / 10$ & $0: 08: 49$ & Telefone \\
\hline 4 & & FAZ. FURNA DO MATEIRO & Proprietário & $19 / 05 / 10$ & $0: 16: 26$ & IN LOCO \\
\hline 5 & & FAZ. CALIFÓRNIA & Gerente & $21 / 05 / 10$ & 1:00:20 & IN LOCO \\
\hline 6 & & FAZ. RROMY & Gerente & $22 / 05 / 10$ & $0: 35: 50$ & Telefone \\
\hline 7 & & CONFIN. BERTIN & Gerente de Rastreabilidade & $27 / 05 / 10$ & $0: 26: 46$ & Telefone \\
\hline 8 & & FAZ. ACARÁ & Gerente & $31 / 05 / 10$ & 0:38:07 & IN LOCO \\
\hline 9 & & GRUPO MACAÉ & Proprietário & $04 / 06 / 10$ & 0:50:09 & IN LOCO \\
\hline 10 & & \multirow{3}{*}{ FAZ. CONFORTO } & Gerente & $03 / 06 / 10$ & $0: 41: 37$ & \multirow{3}{*}{ IN LOCO } \\
\hline 11 & & & Encarregado de Escritório & $03 / 06 / 10$ & 0:26:00 & \\
\hline 12 & & & Super.de Rastreabilidade & $03 / 06 / 10$ & $0: 16: 44$ & \\
\hline \multirow[t]{2}{*}{13} & FRIGORÍFICO & JBS & Rastreabilidade & $16 / 04 / 10$ & $0: 36: 34$ & IN LOCO \\
\hline & & & & TOTAL & $8: 37: 57$ & \\
\hline
\end{tabular}

Fonte: Dados da Pesquisa

Para tratamento dos dados das entrevistas utilizou-se uma análise qualitativa (COLLINS e HUSSEY, 2005). Primeiramente, foram transcritas todas as entrevistas com cada um dos diferentes elos da cadeia (unidades incorporadas), bem como dos representantes de entidades de classe, fornecedores de TIMS, certificadoras, criadores, indústria frigorífica e traders. Em seguida, cada entrevista foi analisada utilizando-se a técnica de Análise de Conteúdo (BARDIN, 2009). Para a análise de conteúdo foram consideradas as seguintes categorias de análise:

- Utilização de TIMS na cadeia pesquisada - envolvendo subcategorias como: quais TIMS eram utilizadas; de que forma;

- Rastreabilidade - envolvendo a compreensão sobre como a rastreabilidade é tratada na cadeia; quais ferramentas são utilizadas para garantir a rastreabilidade e qual o uso (ou não) das TIMS para rastreabilidade;

- Impactos das TIMS para gestão, bem como demais mudanças ou inovações decorrentes da sua utilização em cada elo e na cadeia pesquisada como um todo.

Após a análise de conteúdo conforme as categorias anteriormente indicadas, gerou-se um texto para apresentar os resultados da pesquisa e produziu-se, ao final da análise de cada unidade incorporada (elos da cadeia) um quadro-resumo para facilitar o entendimento. Fez-se então a consolidação dos resultados da pesquisa em quadros-resumo para sintetizar os resultados contemplando todas as unidades incorporadas; e, por fim, cruzou-se os dados dos quadros-resumo com o referencial teórico, gerando-se a discussão dos resultados, os quais serão apresentados a seguir. 


\section{ANÁLISE DOS RESULTADOS}

Nesta seção encontra-se a apresentação e discussão dos resultados da pesquisa. Para facilitar o entendimento, os resultados serão apresentados em três subseções, conforme as categorias de análise anteriormente indicadas: (1) TI/TIMS utilizadas na cadeia bovina pesquisada; (2) o sistema de rastreabilidade e as TI/TIMS na cadeia; (3) as decorrências da utilização das TI/TIMS para a gestão da cadeia, mudanças e inovações decorrentes do uso.

\subsection{TI/TIMS Utilizadas na cadeia bovina}

Os resultados da pesquisa apontam que algumas TIMS, como por exemplo: notebooks, celular, rádio, leitores de código de barras, brinco SISBOV e GPS estão sendo utilizadas pela maioria das empresas entrevistadas. Apenas uma (1) propriedade, coincidentemente a de menor volume de produção, não faz uso de TI/TIMS. A razão pela não adoção está diretamente relacionada ao custo/benefício, baixa produção e custo elevado de implantação.

O notebook é o dispositivo móvel mais utilizado pelos participantes da pesquisa. Em segundo lugar apresenta-se o celular. Apenas uma (1) propriedade, a de menor produção, não possui sinal de internet. Apesar de não constar do levantamento de dados em campo, observou-se o uso frequente de smartphones pelos entrevistados.

Os brincos (SISBOV) com código de barras são utilizados por todas as propriedades para garantir a rastreabilidade e atender as exigências legais. Já o brinco eletrônico, em geral, é utilizado como dispositivo de controle gerencial do rebanho durante o manejo. Apenas três (3) propriedades estão operando com este dispositivo. Os brincos e leitores de RFID também estão sendo testados por duas (2) propriedades. Uma das empresas destaca duas dificuldades de implantação: o bastão de leitura que não lê chips de outros fabricantes e a perda de dados gravados no brinco.

O brinco com o leitor de código de barras está bem disseminado. É utilizado por sete (7) das nove (9) empresas entrevistadas, porém, a grande maioria aponta problemas com a utilização deste dispositivo. Os ambientes de pasto e curral contribuem para o acúmulo de barro, terra e fezes nos brincos, o que impossibilita uma leitura rápida. A balança eletrônica é utilizada por oito (8) das nove (9) propriedades entrevistadas, além do frigorífico.

A falta de uma regulamentação por parte do Governo Federal no sentido de estabelecer um padrão para os dispositivos móveis provoca desordem no mercado fornecedor 
Análise da utilização de Tecnologias da Informação Móveis e Sem Fio (TIMS) na cadeia bovina: um estudo de caso no estado de Goiás

de TIMS. Até o momento o governo federal não reconhece o dispositivo eletrônico como um meio para se garantir a rastreabilidade. Este pode ser um impeditivo ao avanço das TIMS na pecuária de corte de Goiás.

A aplicação da tag de RFID foi observada em duas (2) fazendas. Em ambas a aplicação é idêntica, utiliza-se para identificar os coxos e registrar automaticamente os abastecimentos de ração. Angeles (2005) afirma que a identificação por RFID é um exemplo de TIMS que promete reduzir os gaps de informação na cadeia de suprimentos. Goltman, Gadh e Michael (2008) também afirmam que as TIMS têm um papel no apoio à concorrência na cadeia de suprimentos, em especial o RFID, que aumenta a transparência entre os elos da cadeia e gera benefícios como: redução do tempo para reorganizar transferências de materiais; melhora o rastreamento de produtos individuais; proporciona um melhor planejamento e otimização de estoque e ativos reutilizáveis.

Para Lefebvre et al. (2006) e Kärkkäinen e Holmström (2002) o RFID no SCM é uma tecnologia que aumenta o nível de integração dos processos na relação B2B, promove o compartilhamento de informações entre as operações, gerando grandes mudanças na política, cultura, desempenho e estrutura organizacional. Porém, em geral, não se observa na cadeia bovina pesquisada, qualquer movimento neste sentido. As tecnologias empregadas ou em fase de implantação são para atender necessidades individuais e específicas de controle do negócio e não da cadeia como um todo.

Quatro das propriedades pesquisadas utilizam o GPS. Em todas há uma semelhança na utilização, em geral, pelos tratoristas na plantação, adubação, roçagem ou na demarcação de pastos. Strassner e Schoch (2002) reconhecem o GPS como uma TIMS que possibilita ao gestor ter o posicionamento (em termos de coordenadas) da localização do objeto monitorado. Observa-se que este dispositivo não é utilizado para monitorar objetos ou ativos, mas sim para medir produtividades (no caso do tratorista) ou então guiar o operador de máquina no sentido de garantir a realização do trajeto pré-estabelecido.

Dentro da cadeia observa-se que a empresa frigorífica pesquisada faz uso de um dispositivo e de uma modalidade de software que não aparecem nos demais elos: o pocket PC e sistemas de informação via web. Em termos de infraestrutura e mão de obra especializada em tecnologia, a empresa frigorífica pesquisada é a única organização que possui equipe própria para cuidar do desenvolvimento e implantação de novas TI/TIMS, inclusive com projetos de mobilidade. Nos elos anteriores (produtor) os serviços especializados de TI/TIMS são contratados de especialistas na área sediados em cidades afastadas das propriedades. Já na

REAd | Porto Alegre - Edição 77 - N 1 - janeiro/abril 2014 - p. 140-169 
extremidade da cadeia mais próxima ao mercado, o trader, não identificou-se aplicação de TI/TIMS. A figura 1 demonstra alguns dos dispositivos de TIMS utilizados no contexto pesquisado.

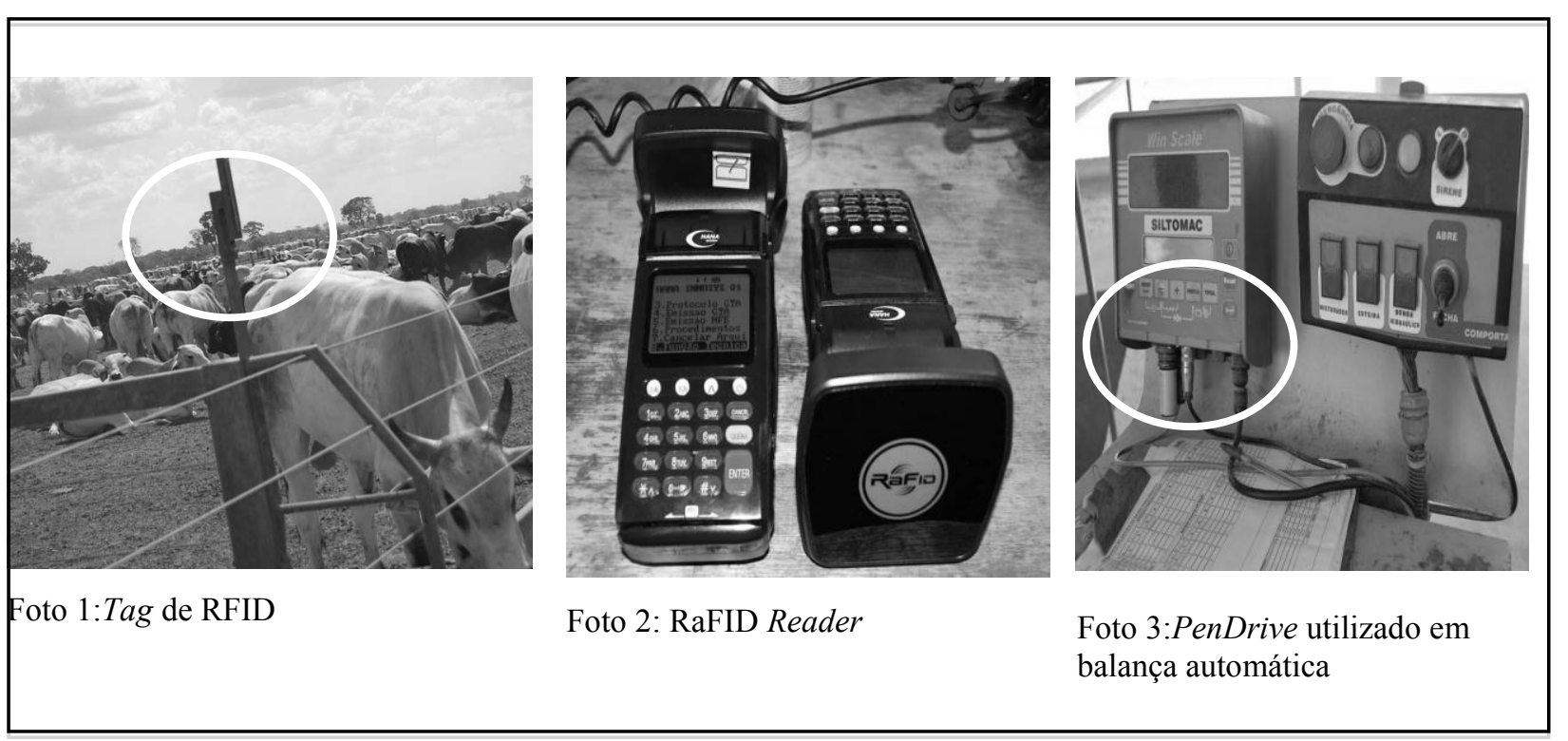

Figura 1- Alguns dispositivos TIMS identificados

Fonte: Autores

Dentre os principais motivadores para adoção das TI/TIMS destacam-se o prêmio pago pelo animal rastreado e as exigências do sistema de rastreabilidade. Apenas uma propriedade, a segunda menor em produtividade, apontou a necessidade de controle e interesse pessoal como sendo o principal motivador para adoção das TI/TIMS. Observou-se que as empresas que focaram no prêmio, passaram a reconhecer ganhos de gestão (controles e acesso à informação) com a aplicação das TI/TIMS, enquanto que empresas que focaram em atender as exigências do SISBOV (inclusive a empresa frigorífica) passaram a reconhecer ganhos de produtividade.

Mesmo diante desse cenário de utilização das TI/TIMS constata-se que existem dificultadores que comprometem o avanço no uso dessas tecnologias na pecuária de corte, tais como: infraestrutura básica deficitária (energia e telecomunicações); falta de mão de obra qualificada; clima.

Frente a problemas com energia elétrica, descargas elétricas e baixa qualidade no sistema de telecomunicações, qualquer esforço para implantação de TI/TIMS será em vão. Nem mesmo o maior produtor, com a melhor condição financeira, conseguirá sanar tais problemas básicos de infraestrutura. Pesquisando-se a literatura, verificou-se no trabalho de Saccol, Manica e Elaluf-Calderwood (2011) que outras organizações já verificaram essas 
Análise da utilização de Tecnologias da Informação Móveis e Sem Fio (TIMS) na cadeia

bovina: um estudo de caso no estado de Goiás

baixas condições de infraestrutura, especialmente no interior do Brasil, para o desenvolvimento de projetos de mobilidade. Segundo as autoras, o IBGE teve dificuldades na realização do Censo 2007, que incluiu um censo agropecuário, corroborando as dificuldades apontadas neste estudo. Observa-se que este cenário precisa ser considerado nas políticas públicas relacionadas à infraestrutura de telecomunicações no País.

A baixa qualificação da mão de obra do campo é outro empecilho para o avanço do uso da tecnologia. Ficou evidenciado que a tecnologia avançou em vários aspectos, tais como: funcionalidade, aplicabilidade e custo, porém, sem recursos humanos capazes de extrair dessa tecnologia informações relevantes para o negócio, ela perderá seu valor. É preciso profissionalizar o homem do campo para que este compreenda a complexidade das relações comerciais e organizacionais, buscando prover soluções proativas ao negócio. A falta de qualificação é uma ameaça aos projetos de adoção de tecnologia, visto que o funcionário não consegue explorar os recursos disponíveis ou ainda pode recusar-se a utilizá-la. Questões culturais como conservadorismo e tradicionalismo também são apontadas como barreiras para a difusão das TI/TIMS.

Percebe-se, porém, dois aspectos que podem reverter esses elementos dificultadores. A primeira se dá quando do acesso e conhecimento das informações do negócio. A segunda situação identificada é que, na medida em que o processo sucessório da gestão da propriedade/empresa inicia-se, avança-se também no uso de tecnologias. Conclui-se que há uma tendência maior de uso de TI/TIMS pela nova geração de proprietários e gestores das empresas da cadeia pesquisada.

A necessidade de acesso às informações da atividade estimula os produtores a investirem em tecnologia. Segundo Siau e Shen (2002) as TIMS serão ferramentas importantes para apoiar os tomadores de decisão que precisam atender prontamente às necessidades do mercado, melhorando a comunicação organizacional e os relacionamentos com seus clientes e fornecedores. Para Kalakota e Robinson (2002) as TIMS têm impacto significativo no gerenciamento de estoque, logística, entrega, rastreamento, recebimento, coleta de dados e gerenciamento da expedição.

De acordo com os dados coletados na indústria frigorífica pesquisada, as necessidades são outras. Assim, o que a motiva a utilizar as TI/TIMS são: necessidade de controle rigoroso; aumento de produtividade; necessidade de acesso à informação de forma rápida e segura; necessidade de controles estatísticos de toda a produção; exigências do mercado externo (rastreabilidade e garantia de procedência); 
Eliane Gomes Da Costa, Amarolinda Zanela Klein \& Luciana Marques Vieira

Observou-se que em alguns elos (cria e recria) a aplicação das TI/TIMS é menos difundida e aplicada. Isso se evidencia pela não obrigatoriedade de uso do sistema de rastreabilidade. Já no elo de engorda, todas as empresas entrevistadas apresentaram aplicações bem estruturadas de TI/TIMS. Este movimento pode ser justificado pela proximidade do elo engorda com o frigorífico. As quatro (4) maiores propriedades do estudo já estão se preocupando em implantar tecnologias de RFID para aumentar a produtividade nas fazendas.

\subsection{O Sistema de Rastreabilidade e o uso da TI/TIMS na cadeia}

As percepções em relação ao sistema de rastreabilidade brasileiro são bastante divergentes entre os elos da cadeia. Para algumas empresas é um compromisso político, para outras, um sistema lento e burocrático (um problema para o produtor). Outras afirmam ainda que o modelo proposto de controle individual do animal é um excelente modelo de gestão e, por fim, também é compreendido como sendo uma tentativa de equalizar a concorrência dos países em desenvolvimento frente aos produtores europeus.

Os resultados da pesquisa apontam que a exigência da rastreabilidade pelo mercado Europeu provocou uma nova forma de comercialização (compra) por parte do frigorífico. Este passou a pagar um prêmio pelo boi rastreado, o que incentivou os produtores a entrarem no SISBOV, contribuindo para a difusão do uso das TIMS no elo produtor.

Para a grande maioria dos entrevistados a falta de infraestrutura básica (computador, sistema de informação, acesso ao Mapa e veículos) nas Agrodefesas, o excesso de documentação, a morosidade do sistema de registro e a movimentação (produtor -> certificadora -> Mapa), além do rigor nas penalidades para o produtor, são as principais razões para caracterizar o sistema de rastreabilidade brasileiro como burocrático e dispendioso. A figura 2 demonstra todos os elos e entidades envolvidas na cadeia bovina, incluindo aquelas ligadas à questão da rastreabilidade e tecnologias utilizadas para isso. Cabe destacar que tal ilustração foi elaborada a partir dos dados obtidos da pesquisa.

REAd | Porto Alegre - Edição 77 - N 1 - janeiro/abril 2014 - p. 140-169 
Análise da utilização de Tecnologias da Informação Móveis e Sem Fio (TIMS) na cadeia bovina: um estudo de caso no estado de Goiás

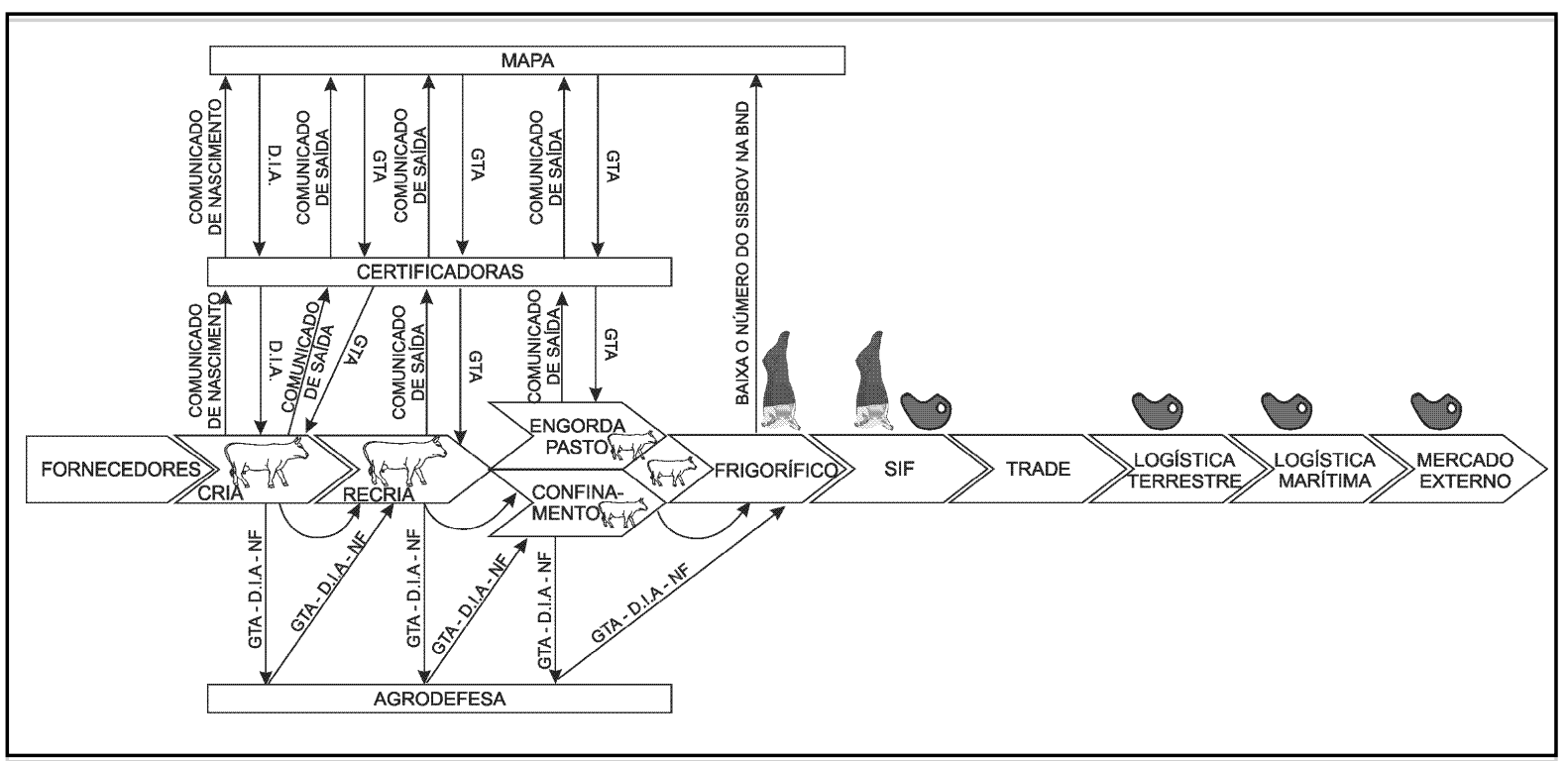

Figura 2 - A movimentação animal no sistema de rastreabilidade do Brasil Fonte: Elaborada a partir de dados da pesquisa

Observou-se que ao mesmo tempo em que o sistema de rastreabilidade brasileiro estabelece rigorosos controles na operacionalização (exemplo: o animal não pode perder um brinco), por outro lado dá margem para controle tardio do rebanho. Isso acontece porque a rastreabilidade é mais intensamente trabalhada no elo de engorda, elo mais próximo ao frigorífico. Como a adesão ao SISBOV é facultativa e o "prêmio pelo boi rastreado" só ocorre na fase da engorda, os demais elos (cria e recria) não se preocupam em garantir a rastreabilidade. Uma propriedade que trabalha somente com engorda pode adquirir animais de dois tipos de propriedades: uma propriedade comum e outra com registro no SISBOV. Adquirindo animais de uma propriedade comum, o pecuarista precisará deixá-los em noventena para conseguir autorização de abate. Adquirindo-os de uma propriedade credenciada SISBOV, em teoria, só precisaria mantê-los por 45 dias na propriedade para conseguir a autorização de abate. Porém, na prática, o volume de transações entre fazendas certificadas SISBOV são minoria. A prática habitual de mercado sugere que a rastreabilidade no Brasil é parcial. De acordo com um dos produtores, um animal chega ao ponto de abate com 30 meses de vida. De acordo com as regras do SISBOV, registrando-se apenas os três últimos meses, ou seja, $10 \%$ de sua vida o Mapa entende que o animal está rastreado.

Neste caso, a noventena pode ser classificada como um dificultador para a adoção das TI/TIMS ao longo de toda a cadeia. Acredita-se que, havendo a obrigatoriedade de rastrear o animal desde a cria, muito provavelmente toda a integração da cadeia produtiva seria alterada, inclusive a necessidade de trocas de informações ao longo da produção, como forma das REAd | Porto Alegre - Edição 77 - N 1 - janeiro/abril 2014 - p. 140-169 
Eliane Gomes Da Costa, Amarolinda Zanela Klein \& Luciana Marques Vieira

empresas tornarem-se mais competitivas. De acordo com Machado e Zylbersztajn (2004) o sucesso do modelo britânico se deu em função da participação intensiva do governo, através de fiscalizações rígidas e aplicação de elevadas multas para os pecuaristas infratores do sistema.

É importante também destacar que, com base nos resultados encontrados nesta pesquisa, fica evidente que o sistema de rastreabilidade é uma exigência da regulamentação internacional, e não da demanda do consumidor. Ou seja, as informações que a rastreabilidade produz são somente para uso dos elos da cadeia e dos órgãos regulamentadores, logo, não é um elemento de diferenciação da carne, mas sim de controle de gestão de risco na cadeia de suprimentos.

\subsection{Decorrências do uso de TI/TIMS para a Gestão}

Com a utilização de TI/TIMS nas empresas entrevistadas, percebe-se que, do ponto de vista gerencial, os seguintes ganhos são consensualmente reconhecidos: controle de estoque; controle de custos individuais (por animal); controle da produção (volume e tempo), melhor previsão de vendas; controle de produtividade dos funcionários; gestão dos ganhos e perdas por animal; redução nos erros de lançamento; aumento da eficiência do manejo; maior segurança para o proprietário/acionista; melhor gestão da alimentação; melhoria da qualidade da informação; melhoria da disponibilidade da informação.

Apesar dos ganhos citados acima, observa-se que não há ações no sentido de integrar a cadeia (por meio de trocas de informações) e que as soluções de RFID são pouco disseminadas, encontrando-se em fase de implantação. Mais uma vez, os principais dificultadores destas práticas são a falta de infraestrutura básica, a energia instável e as redes de telecomunicações precárias, além do custo de aquisição da tecnologia e da falta de conhecimento das necessidades de sistemas de informações e configurações tecnológicas pelas propriedades rurais pesquisadas. Adicionalmente, o suporte tecnológico, dadas as distâncias, torna-se economicamente pouco atrativo para os fornecedores de tecnologia. A falta de empresas especializadas no contexto agropecuário também é apontada como barreira para a adoção das TIMS. Para Bowersox, Closs e Stank (2000) para que haja uma troca confiável e eficiente de informação se faz necessária a utilização de tecnologias tais como internet (para permitir a conexão entres os elos), RFID (para captar informação em diversos momentos do processo produtivo e da cadeia de abastecimento), computadores (para 
Análise da utilização de Tecnologias da Informação Móveis e Sem Fio (TIMS) na cadeia bovina: um estudo de caso no estado de Goiás

processar os dados e transformá-los em informação) e celulares ou outros dispositivos móveis (para coletar e transmitir informações).

Mesmo com as dificuldades de uso das TIMS, observa-se que o acesso à informação modificou a forma de se pensar a fazenda. Percebeu-se em todas as propriedades visitadas uma série de ações e características que remetem a uma empresa profissionalizada, como por exemplo: controle de ponto; escritório estruturado; sala de servidor; grupo gerador; refeitório; portaria com controle de acesso; alojamento; estacionamento para visitante; recepcionista; sala de reuniões; sala de treinamento.

Nas visitas in loco, principalmente nas propriedades rurais, ficou evidente o quanto as TIMS modificaram o dia-a-dia nas fazendas, pois percebeu-se o uso de rádios, telefones celulares e notebooks, pelos funcionários, no desenvolvimento de suas atividades. Nos currais os leitores de código de barras, computadores portáteis, rede wireless e sistemas de informação proporcionam acesso a informações de forma rápida e segura. A tomada de decisão tornou-se mais assertiva. Porém, segundo Basole (2008), estes benefícios são apenas a ponta do iceberg, há muito que se desenvolver no sentido de transformar as organizações, a cadeia e o mercado, com o uso da mobilidade empresarial.

Mesmo diante das evidências de ganhos de aplicação de TI/TIMS, observa-se que as TIMS utilizadas, como brincos (com código de barras), leitores de código de barras e sistemas ERP podem não ser as melhores alternativas ainda. Segundo Strassner e Schoch (2002), com estas tecnologias erros humanos e atraso (delay) no acesso à informação são factíveis e esperados, tornando o sistema ineficiente. Os autores afirmam que, com menos intervenção humana e mais utilização de recursos tecnológicos autônomos (RFID, sensores, localizadores) é possível melhorar ainda mais o desempenho na cadeia.

\section{CONSIDERAÇÕES FINAIS}

O principal objetivo deste artigo foi analisar a utilização das Tecnologias de Informação Móveis e Sem Fio (TIMS) nos diferentes elos da cadeia bovina, bem como, identificar possíveis desafios, inovações e/ou oportunidades decorrentes desse uso por meio de um estudo de caso da cadeia da pecuária de corte no estado de Goiás.

Conclui-se que, em geral, as TIMS são utilizadas para controles internos de gestão e rastreabilidade em algumas organizações pertencentes aos diferentes elos da cadeia. Percebeu-se que as TIMS contribuíram significativamente para o avanço nas práticas de 
Eliane Gomes Da Costa, Amarolinda Zanela Klein \& Luciana Marques Vieira

gestão das operações das empresas pesquisadas que as utilizam, mas não para a integração da cadeia. Ou seja, houve melhorias nos processos operacionais específicos das organizações, mas não houve inovações ou mudanças significativas no que tange à estrutura da cadeia e mesmo, no processo de rastreabilidade com o uso das TIMS na cadeia como um todo, o que poderia gerar-lhe aumento de produtividade e competitividade. Portanto, estas organizações ainda utilizam as TIMS de uma forma muito operacional e pouco estratégica, perdendo uma oportunidade de integrar as informações de todos os elos, a fim de tornarem-se mais competitivas como cadeia de negócios.

A falta de infraestrutura de energia elétrica e de telecomunicações, a falta de mão de obra qualificada, bem como suporte às propriedades por parte dos fornecedores de tecnologia e as intempéries climáticas são as principais barreiras para adoção das TIMS. Os custos elevados de acesso à tecnologia, o conservadorismo ao longo da cadeia e a falta de empresas de tecnologia especializadas no contexto da pecuária são outras restrições destacadas para a adoção das TIMS.

Os ganhos reconhecidos pelas empresas usuárias dessa tecnologia na cadeia pesquisada estão relacionados a controles de estoque, produção, produtividade, segurança para os proprietários/acionistas, disponibilidade e qualidade das informações. Na produção destaca-se como benefícios o controle individual dos animais, a redução nos erros de lançamento e uma melhor gestão nutricional. Com a utilização de brincos com códigos de barra ou eletrônicos (RFID) para controle individual do animal associado a um sistema de informação, é possível garantir a rastreabilidade.

Entretanto, quanto à gestão da cadeia pesquisada, apesar da literatura sugerir que TIMS podem ser utilizadas para melhorar a gestão da cadeia de suprimentos, conforme já foi comentado, não foram identificadas, na pesquisa, ações relevantes nesta direção. Assim, os resultados deste estudo trazem uma contribuição de ordem prática, pois sinalizam que é necessário o estabelecimento de políticas públicas assegurando que a infraestrutura básica (por exemplo, energia elétrica e telecomunicações) chegue ao meio rural da mesma forma como nas grandes cidades. Sem essa infraestrutura as dificuldades para adoção das TIMS são ampliadas. Esse é o ponto mais crítico levantado pela pesquisa. Outro aspecto considerado crítico é a adesão voluntária ao sistema de rastreabilidade brasileiro. Esta voluntariedade prejudica a integração da cadeia no elo produtor.

REAd | Porto Alegre - Edição 77 - N 1 - janeiro/abril 2014 - p. 140-169 
Análise da utilização de Tecnologias da Informação Móveis e Sem Fio (TIMS) na cadeia bovina: um estudo de caso no estado de Goiás

Portanto, entende-se que há um caminho à frente a ser percorrido no que tange a investimentos em infraestrutura básica, qualificação de mão-de-obra e regulamentação para que inovações tecnológicas, de processos e produtos.

Ainda como contribuições de ordem prática, recomenda-se para a cadeia estudada o desenvolvimento de ações de integração, tais como:

- Adoção de TIMS ao longo de toda a cadeia, garantindo a rastreabilidade desde a origem (local de nascimento). Se o elo cria e recria utilizarem um dispositivo eletrônico de identificação e garantirem os registros junto ao SISBOV, poderão exigir um preço diferenciado pelo animal e, por outro lado, o elo engorda reduzirá 45 diárias de confinamento.

- Investir em um sistema integrado de gestão que facilite a troca de informações ao longo da cadeia, estabelecendo-se um padrão de troca de informações. Neste caso, todos os elos ganham em produtividade quando da movimentação de entrada e saída de animais das propriedades.

- Estabelecer padrões tecnológicos para o setor, objetivando a redução dos custos de aquisição.

- Integrar o SISBOV aos sistemas utilizados nas propriedades, eliminando um intermediário (certificadoras) para registrar as movimentações. Neste caso, as certificadoras focariam suas atividades na garantia do sistema de rastreabilidade (auditorias).

Do ponto de vista teórico, a análise das formas de utilização das TIMS, possíveis mudanças e inovações decorrentes dessa utilização na cadeia pesquisada são geradoras de insights para outras cadeias com características e contextos semelhantes. Verifica-se que a literatura sobre TIMS muitas vezes toma um caráter técnico (foco na tecnologia em si), quando poder-se-ia avançar no entendimento do potencial da sua utilização para inovações e mudanças no contexto organizacional e especialmente no contexto inteorganizacional (cadeia), com o que este artigo colabora.

A contribuição de ordem teórica deste artigo também ocorre na medida em que ele discute conceitos, processos e papéis na cadeia produtiva estudada, utilizando referencial teórico de duas áreas distintas (TI e cadeias de suprimentos), o que se mostra útil e pode ser feito em outros estudos de cadeias agroalimentares que utilizam rastreabilidade (como a de frutas, por exemplo).

REAd | Porto Alegre - Edição 77 - N 1 - janeiro/abril 2014 - p. 140-169 
Quanto às oportunidades para pesquisas futuras destacam-se: pesquisar sobre a difusão do uso dos dispositivos eletrônicos (brincos de RFID) para identificação animal na cadeia pesquisada e suas decorrências; a necessidade de sistemas de informação rodando em ambiente web (para acesso por diferentes dispositivos, tanto fixos quanto móveis) que dêem suporte aos processos da cadeia de gado, especialmente para a rastreabilidade; estruturação do comércio eletrônico (m-commerce) como forma de integrar a cadeia; a necessidade de capacitação da mão de obra no meio rural, que pode ser feita, por exemplo, por meio da educação à distância (EAD); a criação de negócios de tecnologia (sistemas e dispositivos eletrônicos) voltados ao setor em questão, com mão de obra e soluções adequadas às necessidades do pecuarista; as novas gerações assumindo os negócios familiares, estimulando a adoção da tecnologia (inclusive TIMS); necessidade de controles da rastreabilidade e de gestão inovadores com o uso de TIMS.

Outra sugestão que pode agregar tanto ao meio acadêmico quanto ao setor estudado é uma pesquisa que indique o ponto de equilíbrio financeiro para adoção de TIMS na cadeia, em especial o RFID, por se apresentar como uma solução mais confiável e completa. Sugerese que uma pesquisa semelhante a esta também seja realizada com pequenos pecuaristas. Por fim, propõe-se que trabalhos futuros utilizem uma abordagem quantitativa e de maior abrangência territorial para que se consiga propor generalização estatística dos resultados aqui encontrados.

Como limitações do trabalho destacam-se: (1) foram entrevistadas poucas propriedades nos elos de cria e recria, o que pode distorcer a análise; (2) quanto ao elo frigorífico, mesmo fazendo parte desta pesquisa o maior processador de carne do mundo, sugere-se entrevistar outros players para confrontar realidades, a mesma sugestão aplica-se ao elo trader; (3) não foram entrevistados representantes do Mapa e da Agrodefesa para validar a percepção dos elos da cadeia; (4) dentro da caracterização da cadeia da pecuária de corte para exportação sugere-se entrevistar empresas de logística terrestre e marítima, que também não foram contempladas neste estudo.

\section{REFERÊNCIAS}

ANGELES, Rebecca. RFID Technologies: supply-chain applications and implementations issues. Information Systems Management, p. 51-65, 2005. 
Análise da utilização de Tecnologias da Informação Móveis e Sem Fio (TIMS) na cadeia bovina: um estudo de caso no estado de Goiás

ASSOCIAÇÃO BRASILEIRA DE INDÚSTRIAS EXPORTADORAS DE CARNE.

Rebanho Bovino Brasileiro. Disponível em: 〈http://www.abiec.com.br/3 rebanho.asp $>$. Acesso em: 07 out. 2011.

BARDIN, L. Análise de Conteúdo. Lisboa: Edições 70, 2009.

BASOLE, R. C. Enterprise mobility: Researching a new paradigm. Information Knowledge Management, 7, p. 1-7, 2008.

BOWERSOX, D. J.; CLOSS, D. J.; STANK, T. P. Ten mega-trends that Will revolutionize supply chain logistics. Journal of Business Logistics, v.21, n. 21, p.1-16, 2000.

BRASIL. Ministério da Agricultura e do Abastecimento (MAPA). Portaria ${ }^{\circ}$ 46, de 10 de fevereiro de 1998. Disponível em <http://www.agricultura.gov.br/>. Acesso em 04 abr. 2009.

BRASIL. Ministério da Agricultura, Pecuária e Abastecimento. Cadeia produtiva da carne bovina. Ministério da Agricultura, Pecuária e Abastecimento, Secretaria de Política Agrícola, Instituto Interamericano de Cooperação para a Agricultura; Antônio Márcio Buainain e Mário Otávio Batalha (coordenadores). - Brasília : IICA : MAPA/SPA, 2007. 86 p. Agronegócios; v. 8 .

BRASIL. Instituto Brasileiro de Geografia e Estatística (IBGE). Produção da Pecuária Municipal. Ministério do Planejamento, Orçamento e Gestão,v.37, p.1-55, 2009.Disponível em <http://www.ibge.gov.br/home/estatistica/economia/ppm/2009/ppm2009.pdf $>$. Acesso em 04 abr. 2009.

CÓCARO, H; JESUS, J. C.S., Impactos da implantação da rastreabilidade bovina em empresas rurais informatizadas: estudo de caso. Journal of Information Systems and Technology Management, v.4, n.3, p.353-374, 2007.

COLLINS, J.; HUSSEY, R. Pesquisa em administração. Porto Alegre: Bookman, 2005.

COLTMAN, T.; GADH, R.; MICHAEL, K., RFID and supply chain management: introduction to the special issue. Journal of Theoretical and Applied Electronic Commerce Research, v.3, n.1, p.3-7, 2008. Disponível em:

$\langle$ http://ro.uow.edu.au/cgi/viewcontent.cgi?article=1593\&context=infopapers $>$. Acesso em: 09 out. 2009.

CONCEIÇÃO, J.C.P.R.; BARROS, A.L.M. Certificação e rastreabilidade no agronegócio: instrumentos cada vez mais necessários, 2005. Texto para discussão $\mathrm{N}^{\circ} 1122$, Instituto de Pesquisa Econômica Aplicada. Disponível em: 〈http://www.ipea.gov.br $>$ Acesso em: 26 dez. 2008. 
Eliane Gomes Da Costa, Amarolinda Zanela Klein \& Luciana Marques Vieira

CRESWELL, J. W. Projeto de pesquisa, métodos qualitativo, quantitativo e misto. Porto Alegre: Bookman, 2007.

GOLAN; E., et. al. Traceability in the U.S. food supply: economic theory and industry studies. United States: Depto. of Agriculture. Economic Research Service, 2003. Disponível em: 〈http://www.food.gov.uk/news/newsarchive/2002/apr/traceability>. Acesso em 10 mai. 2009.

HAIR, Jr., et. al. Fundamentos de métodos de pesquisa em administração. Tradução Lene Belon Ribeiro. Porto Alegre: Bookman, 2005.

KALAKOTA, R.; ROBINSON, M. M-business: tecnologia móvel e estratégia de negócios. Porto Alegre: Bookman, 2002.

KÄRKKÄINEN, M.; HOLMSTRÖM, J. Wireless product identification: enabler for handling efficiency, customization and information sharing. Supplay Chain Management: an International Journal, v.7, n.4, p.242-252, 2002.

LEFEBVRE, L. A.; LEFEBVRE, E.; BENDAVID, Y.; WAMBA, S.F.; BOECK, Harold. RFID as an enabler of b-to-b e-commerce and its impact on business processes: a pilot study of a supply chain in the retail industry. Proceedings of the $39^{\text {th }}$ Hawaii International Conference on System Sciences, 2006. Disponível em:

$<$ http://library.wur.nl/wasp/bestanden/LUWPUBRD_00353065_A502_001.pdf $>$. Acesso em 24 out. 2009.

MACHADO, R. T. M.; ZYLBERSZTAJN, D. Coordenação do sistema da carne bovina no Reino Unido: implicações da rastreabilidade e da tecnologia de informação. Organizações Rurais e Agroindustriais, Lavras, v. 6, n. n.1, p. 37-51, 2004.

MACHADO, R. T. M. Rastreabilidade, tecnologia da informação e coordenação de sistemas agroindustriais. São Paulo, 2000. Tese de doutorado, apresentada à Faculdade de Economia, Administração e Contabilidade da Universidade de São Paulo. Disponível em: $<$ http://bdtd2.ibict.br/index.php?option=com_wrapper\&Itemid=39>. Acesso em 22 ago. 2009.

OECD, OCDE. Manual de Oslo, 2004. Disponível em 〈http://download.finep.gov.br/imprensa/manual_de_oslo.pdf $>$. Acesso em 19 out 2012.

MENTZER, J. T.; DeWITT, W.; KEEBLER, J. S.; MIN, S.; NIX, N. W.; SMITH, C. D.; ZACHARIA, Z. G. Defining supplay chain management. Journal of Business Logistics, v. 22, n. 2, p. $1-25,2001$. 
Análise da utilização de Tecnologias da Informação Móveis e Sem Fio (TIMS) na cadeia bovina: um estudo de caso no estado de Goiás

MINISTÉRIO DA AGRICULTURA, PECUÁRIA E ABASTECIMENTO. Cartilha do novo serviço de rastreabilidade da cadeia produtiva de bovinos e bubalinos - SISBOV. Brasília: SDC/ABIEC/CNA/ACERTA, 2006.

ORGANIZAÇÃO DAS NAÇÕES UNIDAS (ONU). Population Aging 2006. Disponível em: 〈http://www.un.org/esa/population/publications/ageing2006chart.pdf > . Acesso em: 28 mar. 2009.

ORGANIZAÇÃO MUNDIAL DE SAÚDE ANIMAL. Código sanitário para animais terrestres: definições gerais e notificação de doenças animais. São Paulo, 2008. Traduzido pelo Conselho Nacional da Pecuária de Corte.

PARABHU, B.S; et al. Win RFID - a middleware for the enablement of radio frequency identification (RFID) based applications. 2006. Disponível em: 〈http://www.psu.edu $>$. Acesso em 24/10/2009.

RESENDE, E. H. S.; LOPES, M. A. Identificação, certificação e rastreabilidade na cadeia da carne bovina e bubalina no Brasil. Lavras: UFLA. 2004. 39 p. (Boletim agropecuário, $58)$.

RIBEIRO, P.; SCAVARDA, A.; BATALHA, M. RFID in the international cattle chain: traceability, context and legislation. Simpósio de Pesquisa Operacional e Logística da Marinha, Rio de Janeiro, 2007.

SACCOL, A. Z.; REINHARD, N. Tecnologias de informação móveis, sem fio e ubíquas:definições, mapeamento do estado-da-arte e oportunidades de pesquisa. RAC, v. 11, n. 4, p. 175-198, 2007.

SACCOL, A. Z.; MANICA, A.; ELALUF-CALDERWOOD, S. Innovation and adoption of mobile technology in public organizations: the IBGE Case. Revista de Administração de Empresas (RAE), v. 51, no. 1, p. 72-83, 2011.

SACCOL, A. Z.A teoria da hospitalidade e o processo de adoção de tecnologias da informação móveis e sem fio. São Paulo, 2005. Tese (doutorado em Administração) Programa de Pós-Graduação em Administração - FEA - Universidade de São Paulo.

SADLER, I.; HINES, P. Strategic operations planning process for manufacturers with a supply chain focus: concepts and a meat processing applications. Supply Chain

Management Journal, v. 7, n. 4 p. 225-241, 2002.

SARAC, A., ; ABSI, N. A literature review on the impact of RFID technologies on supply chain management. International Journal of Production Economics, v. 128, p. 77-95, 2010 .

REAd | Porto Alegre - Edição 77 - N 1 - janeiro/abril 2014 - p. 140-169 
Eliane Gomes Da Costa, Amarolinda Zanela Klein \& Luciana Marques Vieira

SORENSEN, C.; et al. Exploring enterprise mobility: lessons from the field. Information Knowledge Systems Management. v. 7, p. 243-271, 2008.

SORENSEN, C. Enterprise mobility: tiny technology with global impact on work. $1^{\text {a }}$.ed. London: Palgrave Macmillan, 2011.

SCHUMPETER, J. The Theory of Economic Development, Cambridge, Massachusetts: Harvard University Press, 1934.

SECRETARIA DO PLANEJAMENTO E DESENVOLVIMENTO DO ESTADO DE GOIÁS. Produto Interno Bruto dos municípios goianos - PIB 2006. Goiânia, 2008.

SIAU, Keng; SHEN, Zixing. Mobile Commerce Applications in Supply Chain Management. Journal of Internet Commerce, v. 1, n. 3, p. 3-14, 2002.

SMITH, S.; PHILLIPS, P. W. B. Product differentiation alternatives: identity preservation, segregation, and traceability. AgBioforum, v. 5, n. 2, p. 30-42, 2002.

STRASSNER, M., SCHOCH, T., Today's Impact of Ubiquitous Computing on Business Processes, First International Conference on Pervasive Computing 2002, Zurich, p. 62-74, 2002.

VAN de VEN, A. Central Problems in the Management of Innovation. Management Science, no. 5, vol. 32, p. 590-607m 1986.

YIN, R. K. Estudo de caso: planejamento e métodos. Tradução Daniel Grassi. 3. ed. Porto Alegre: Bookman, 2005. 